\title{
Factors Affecting the Performance of Public Sector Practitioners in the Republic of Congo
}

\author{
Gildas Moukouyou-Kouaka ${ }^{1} \&$ Olawumi D. Awolusi² \\ ${ }^{1}$ University of Roehampton, London, UK \\ ${ }^{2}$ Department of Accounting and Finance, College of Economics and Management, Kampala International \\ University, Kampala, Uganda \\ gildas.moukouyou@roehampton-online.ac.uk, awolusi.olawumi@kiu.ac.ug
}

\begin{abstract}
In most of the structures of the public sector in the Republic of Congo, the quality of services provided to the general public has never been of good quality as perceived by the population. Consequently, the purpose of this study is to understand the root cause of inefficiency in the public sector of the Republic of Congo. A descriptive survey was designed for this purpose. Gill et al. (2008) argument on the most preferred use of interviews questionnaires in qualitative research was utilized to gather data from the sampled respondents. The data obtained from the individual's interviews were analysed using SPSS software. The traditional approaches of employee's performance management were analysed and plotted. The results of the study revealed that many employees were not adequately trained to perform their duties; in the meantime, most of these employees have not received any training in the last 10-15 years. Furthermore, it was also revealed that the top management doesn't undertake performance management appraisal and also the latter doesn't promote career development. Therefore, the employees suggested capacity building training. Revision of the salary scale and improvement of working conditions as the things that needs to be changed to improve their performance. Finally, the researcher concluded that among others actions that can be taken there is need to initiate a restructuration of the public sector in the Republic of Congo e.g. by re-introducing an entrance to the public sector examination, introduce performance appraisal management system and establish a career development systems for all categories of employment, to promote the culture of excellence in its structures and improve employee's performance. The novelty of the present study is the fact that the effectiveness of most of the services rendered to the general public in the Republic of Congo has never been investigated using scientific approaches. This study has therefore established the relation between the decisions taken by the top management and their impacts on employee's performance. In the meantime, the study has provided also the evidence on the correlation between the organization's culture and the decisions taken by the top management.
\end{abstract}

Keywords: Top management, Practitioner's performance qualitative research, public sector, Republic of Congo.

\section{Introduction}

The public sector has been largely inefficient in terms of services delivery in many developing countries (Blazi \& Awolusi, 2020; Mukonga \& Awolusi, 2019). The inefficiency in some fields of the public sector has, therefore, been the main reason for which previous researches were conducted on the topic (Arinder, 2016; Van, 1996). However, as practitioners of public services most of the time human values conflicts while serving the public interest. There should not be a disproportion of efficiency, dynamism and expertise while values compete. In the same view, Drafke (2008) highlighted that, as every individual has a set of values every organization has a set of values. Indeed, the practitioners in the public sector have values that might not necessarily align with those of the organization. Furthermore, Arinder (2016) stressed that emotions, beliefs and evidence are often balanced by policymakers in making decisions. In consideration of this theory.

We can assume that this is also applicable to the decisions made in the public sector. In this case, this implies that logically the practitioners of the public sector will not have so many challenges while serving the public interest. This is on the premise that the decision-makers in one way or another have already factored the practitioner's values in the decisions to be taken. However, according to Ojasalo and Tähtinen (2016), the complexity of the public sector decision-making processes make it more challenging for the practitioners of the public sector to collaborate with external actors. Although the complexity of the decision making processes as explained by Ojasalo and Tähtinen (2016) tend to have a significant impact on the performance of the practitioners of the public sector while serving the public interest. This does not necessarily justify the inefficiency in services delivery. In the Republic of Congo, like in many African countries, the structure and the text that govern. 
The management of the public sector have been inherited from the colonial period. Most of these texts might have not been updated since the Country got its independence in 1960. This might not necessarily align with the current context in the Republic of Congo knowing that the society has evolved. The public sector is the first and the biggest employee in the Country, yet much is not known whether these factors must be leading to inefficiency in service delivery since these text dated from the colonial period might no longer fit with the current context of the society. Also, much is not known in the way the employee's performance is managed in this sector that might be having an impact on the services delivery. In the Republic of Congo, when visiting the offices of the public sector such as the hospitals, schools, immigration offices, police posts, structures in charge of providing water, electricity in the cities and rural setup, public administration in charge of providing a birth certificate, nationality certificate, marriage certificate, etc. By moving across the different department of these structures, it is rare to have an environment which is not noisy that give the impression that people are not concentrated.

Also, there is likelihood to notice that in the delivery of their daily activities, there is a lack of creativity and lack of high standard in services delivery. In practice, the public sector should be more creative and keep a high-level standard in services delivery since it serves the general public. However, in the Republic of Congo, the data on the health system, education system, and public administration is not digitalized. Therefore, to get access to country-wide data that can be used as evidence-based to support the problem sated above for this research project was difficult and or even impossible. However, as reported by the Ministry of Communication and Media Spokesperson of the cabinet, during the last session of the cabinet for the year 2018 held on $27^{\text {th }}$ December. The ministers discussed and voted a draft law on the improvement of the services delivery in the public sector. The draft law was to be submitted to the parliament for the Members of the Parliament to review it before its approbation. The draft law was related to the improvement of the quality of the services delivery in the public sector. Therefore, the above scenario and related gaps identified in the literature motivated the present study.

Consequently, the present study aims to examine the factors that affect the performance of the employees in the public sector of the Republic of Congo. However, the specific objectives were as follows:

- Understand how the promotions to higher grades are managed in the public sector in the Republic of Congo.

- Understand whether employees are involved in the decisions making in the public sector in the Republic of Congo.

- Understand whether a system of employee's performance management appraisal is in place in the public sector of the Republic of Congo.

- Understand the retention mechanism for the employees in the public sector of the Republic of Congo.

Therefore, in connection with its specific objectives, the researcher tried to respond to the following questions:

- Does the management undertaking performance management appraisal for the practitioners of the public sector in the Republic of Congo?

- Do the practitioners of the public sector feel the difference made by their work on the general public?

- Do the practitioners of the public sector being rewarded in their work?

- Does the management promote career development for practitioners of the public sector in the Republic of Congo?

- How does the management ensure that the skills of the practitioners of the public sector in the Republic of Congo remain up to date to allow them to perform their daily work?

Researching the selected topic did not only help to understand the factors that affect the performance of the practitioners of the public sector. But, also by conducting this research, instead of trying to establish that dynamism and efficiency which will never be the cardinal values in the public sector, we rather provided to the practitioners of the public services a list of legalistic and ethical prohibitions. In the meantime, a call for excellence. This research also allowed us to engage with employees and decision-makers in their daily experience, having the possibility to observe and dig deeper in the understanding of the factors that affect the employee's performance in the field of the biggest employer which is the public sector. Therefore, the 
researcher developed a practical relevance of employee's performance management practices. This is particularly relevant in public sector organisations where the complexity of problems and the indeterminacy of solutions always require a case sensitive interventions.

In doing so, the researcher explored how public sector accounting practices and techniques can help in solving these problems, without compromising the quality of research (Jönsson \& Lukka, 2005). This also informed others researches to be conducted on the subject. But in dealing with nowadays complexity of the public sector and the social challenges governments have to cope with, researchers need to be more descend from their "ivory tower" to engage with practitioners of the public sector and decision-makers to stop being a neutral observer of the changes but an actor of change themselves. The researcher was not a neutral observer of the reality, but an active actor contributing to the discovery of employee's performance management practices. Moreover, another reason making this research specifically significant is the fact that it will help other researchers in understanding whether managerial decisions made in the public sector are unethical decisions or not and if these managerial decisions are taken with transparency. In that regards it will avoid frustration within the teams and hence positive impact on the employee's performance.

Otherwise, in their research conducted on decision making which tends to have a direct impact on employee's performance, Bonavia \& Brox-Ponce (2018) highlighted that in most of the cases in decision making the role of transparency is less than expected. In the other hand, as in the case of the study conducted by Hwabamungu, et al. (2018) in the case of the public hospitals in South Africa. This research will find its significance in understanding also whether managerial decisions in the public sector must be emphasized on individuals to improve their performance and fulfil the general interest. Given that the structure of most of the fields in the public sector is composed of Head of Service, Head of the office, Head of the section, and employees. Our research's environment was defined within these four components which constitute the circle of the top management that deals with employee's performance management in the public sector. The research was conducted in eight services of Makelekele Town Hall where all categories of employees were targeted irrespective of their age and gender. The employees reached represented the sample of our respondents. However, as stated by the University of Roehampton Online (2015d) "it is important to get people to agree to take part and before we build the whole research project on the results of the survey.

\section{Review of Related Literature}

Conceptual Review: Gildas (2018) highlighted that, the researchers conducted by Trip, et al. (2002) revealed that managerial ability is critical in explaining employee's efficiency. In their study was categorized as follows; goal formulation, planning, monitoring and evaluation. The quality of the decision making steps was reviewed by a panel composed of twenty-six flower producer. This revealed that there are significant correlation and the quality of the decision making on firm efficiency in regards to the firm evaluation and monitoring. The approach used effectively contributed to measuring the input. Phillips, et al. (2014) conducted research which focused on the external factors that can produce a negative impact on the decisionmaking process. This approach entailed measuring the visual cognitive, emotion and usability. The results revealed that these factors affect the employee's post-verdict regarding confidence and performance. Equally another research by Bercu (2013) highlighted that this is a crucial action that has an impact on the public. There is a need to respond to the needs of the people. However, Bercu (2013) further emphasized that several studies on the topic have confirmed that there is a distinction in decision making (which can also affect employee's performance) in the public service in contrast to the private services.

In that regards, the author responded to the following questions: What are the differences in decision making between the public and private sector? Which are the mechanisms used by managers from the public sector to respond to efficiency, rationality and social responsibility? How can managers from public sector adopt the best decisions? The results of the research revealed that, in responding to the above questions, efficiency and effectiveness are not considered as cardinal values in the public sector compared to the private sector. In the other hand, McGuinness (2014), conducted his research on the economic impact of the health system policy in the United States of America that for him influence the public sector decision-making process. The results of his study show that the success or failure of a country's national economy is linked to the goals of the public health goals. This implies that decisions are taken in the public sector which impact employee's 
performance has a significant impact on countries' national economy. In this regards, our research provided then an opportunity for managers in the public sector to understand how important the decisions are taken in their respective area of responsibilities can have an impact at the national level.

Peek et al. (2016), in their research conducted on African-American LGBTI Patients focused on the shared decision-making that can help patients overcome clinical encounters. The results of their research reveal that race, sexual orientation, and gender works in enhancing patient's perception and behaviour in shared decision-making. In the same view, we can assume that managers can also improve the performance of their employees in understanding the influence of their beliefs, feelings and behaviour (e.g. gender, sexual orientation, ethnicity, religion, political views etc.) on the employee's performance. However, there is a need to conduct more researches on the shared decision-making aspect in public services. This will provide a better understanding of the factors listed above in enhancing employee's performance. The below conceptual model was developed based on prior researches conducted on the decision-making process as presented in this literature review. The model was drawn on the intrinsic values of both managers and employees, with the intersectionality brought by the decision-making which most of the time is provided as information sharing during meetings being official or ad hoc. Finally, other factors such as beliefs, feelings, behaviours and understanding concurrently compete and define the employee's performance in the final decision's outcomes that impact the services delivery towards the general public.

Figure1: Conceptual Model of Decision-Making

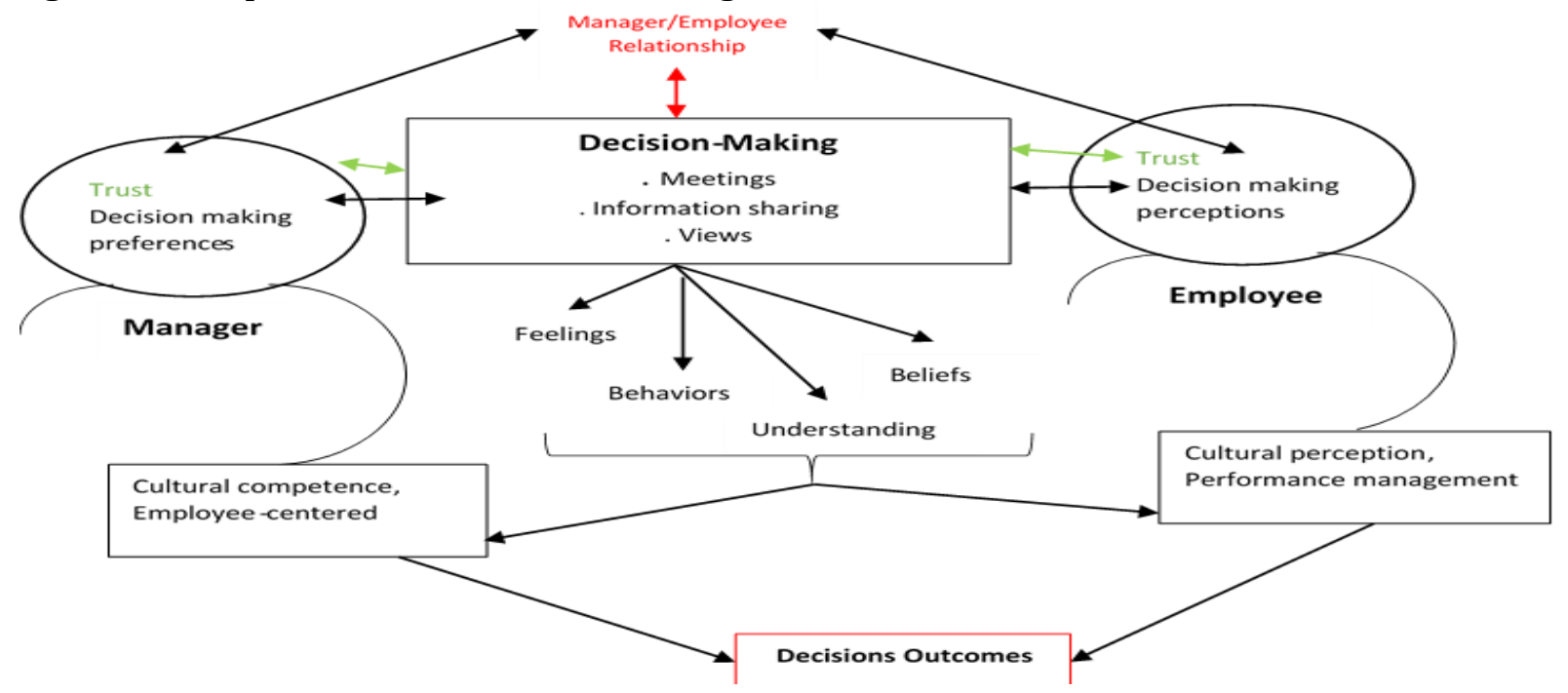

Theoretical Review: Gildas (2018) further stressed that, in a study by Van (1996), there are five sources of decision making: public interest, legal interest, personal interest, organizational interest and professional interest. However, the inefficiency in some fields of the public sector is the reason for conducting the research. Also, the scope of the study looks at the perspective where the employee's values compete while serving the public interest. In that case, normally there should not be a disproportion of efficiency, dynamism and expertise while values compete. On the other hand, one of the common notions in the public sector is that practitioners from that field have several values and roles sets, which constitute the main source for their decisions making. For instance, a practitioner might need to deal with organizational, legal and personal issues at once. However, it is challenging for the employee to identify which of the values is vital for the interest of the public (Gildas, 2018).

Gill et al. (2014) in their research conducted on the decision-making, they focus on the impact of decisionmaking on the group. They state that managers are stakeholders in decision-making and their important role should be to ensure that they create an environment where common purpose lead and employees thrive. They must be in a position where they have to facilitate the work of the organization, neither taking possession nor control it. Although, there are many institutional theories on decision-making; in their research, Ariff \& Karen (2018) classify these theories in decision-making in four approaches as they inform 
the commercial and culture literature other than the professional decision-making which is a whole concept by its own. The following are these four theories of decision-making in the business as explained by Ariff \& Karen (2018):

- Rational decision-making, in this process individuals, set the probability of expected outcomes that will be selected between different action taken;

- Political decision-making, tend to explain the balance of power among people which has an impact on decision-makers' results and assessments;

- The garbage can model of decision-making, this theory is related to managers' lack of control and feeling of uncertainty on internal external factors that are key in decision-making;

- Improvisational decision-making developed based on the shortcomings of the first three theories, this theory defines decision-making as an instant process whereby decision architects control, identify options make use of their institution and their spontaneous action to evaluate.

According to Kozlenkova et al. (2014), the resource-based theory is one of the most appropriate theories used in information structure researches and another field of the business. The theory is used to explain the resources of an organization and the performance of the firm. In this theory, resources enable the organization to design and implement approaches that enhance efficiency and effectiveness. Furthermore, there are many categories of resources that exist in organizations. However, the resources that had been considered here are those suggested by (Grant, 2005) standard. The latter classify resources into three groups, tangible, intangible and human.

Tangible Resources: These include financial resources that support organizations in their capacity of flexibility, investment and physical resources for the organization's potential in production.

Human Resources: These are productive services that employees offer in terms of skills, knowledge, and decision-making ability.

Intangible Resources: These are technology-related and reputation.

Furthermore, RBT (resources-based theory) is presented by several researchers as theoretical and practical guidelines that help to assess organizational performance and resource. Moreover, some researchers suggest that RBT (resource-based theory) can also provide meaningful implications for the study of public agency performance (Lee \& Whitford, 2013). About the theories elaborated above, it was important to understand in our study how did each of these theories relate to the process of the decision-making in the public sector and their impact on employee's performance. First and foremost, in terms of stakeholder's theory, we focused on understanding whether in the public sector; in the process of the decision-making managers find it prominent to create an environment where the common purpose leads.

Also, whether they facilitate the work of the organization instead to possess or control it. Understanding the approach in this theory in contrast to the practice in the public sector was paramount in our research since it provided more information in the role of the managers as one of the stakeholders in the process of decision making in the public sector and the impact of their managerial decisions on the employee's performance. On the other hand, it was also important to understand among the four theories on the decision-making in the business as stated by Ariff \& Karen (2018) which one is predominant in the public sector and how did its impact the performance of the practitioners of the public services. As our study aimed to understand the factors that affect the performance of the practitioners of the public sector, the use of RBT as a theoretical framework for our study was highly appropriate in identifying organizational resources that can improve or enhance the performance in the public sector.

Empirical Review: Gildas (2018) stated that researchers tend to categorize the roles of the practitioner of public services in many ways. "Some researchers are known for concentrating in one area, even with wide views such as Rohr's (1989) concentration on regime values (law and legal tradition) and Frederickson's (1990) emphasis to social equity (public interest). Although many researchers have intentionally divided the roles to cover all the major decision-making bases. Pugh (1991) and Hejka-Ekins (1988) divided genuine sources into the bureaucratic and democratic ethos. Posner \& Schmidt (1994) compared the rugged- 
individualism ethic to the community and co-operation ethic. Three roles were defined by Dobel (1990) who identified regime accountability, personal responsibility.

Prudence as the keys to the ethical decision-making mix." The division of the roles in public services enabled the researchers to organise them in several ways. Therefore, the epistemological perspective of the study of these values may be the foundation of the present study. Moreover, as stated by (Gildas, 2018) the method that was used for the research was the survey through the interview questionnaires tool. The target group for the research were the practitioners from eight services of Makelekele Town Hall where fairness, equity and justice must prevail. The sample size was calculated using the statistical concepts of the confidence interval and confidence level to get the most representative sample size. Before the definition of the sample size meetings and individual consultation was conducted.

To discuss the scope and the aim of the research at this level, the respondents and the dataset were agreed to ensure that both the researcher and the respondents were safe in regards to the confidentiality of the information that was collected. Since the survey was conducted on the practitioners, there was a probability of having challenges in terms of the involvement. Another aspect that was considered is the result of the survey was supposed to be available to the respondents and the information collected to be deleted at the end of the research. Among the strengths of the selected research methodology can be listed are; reliability, flexibility and availability. The survey was easy to administer to the respondents, however, one of its limitations was lack of accountability for the information provided by the respondents since the questionnaires were anonymized and could have been filled by people that were not considered as part of the study. Finally, the data collection tool that was used was interview questionnaires and the technique was the survey. This served as a primary data collection source. To perform data analysis, SPSS software was used.

Relationship Between Dependant and Independent Variables: The study carried out in this research has helped to identify several independents variables such as cultural perception, technology awareness, cultural competencies and managerial competencies that have a significant impact in the process of decision making which is the dependant variable that has a direct impact on employee's performance. These independents variables influence the decisions made by the top management and also their translation into action by the subordinates. The various literature reviewed shows that the methodologies and approaches used in previous studies did not explore much of the research topic. Gildas (2018) and Ariff and Karen (2018) highlights several weaknesses in the previous researches conducted on the selected research topic and for which few have been reviewed.

- Many of the researchers' did not establish a framework that takes into account the complexity of the five sources of decision making.

- Also, many studies failed to establish the basis for exclusion or inclusion criteria of these competing values.

- Out of the twelve researchers that constituted our literature review, none of them provided empirical survey research on tangibles factors that affect the employee's performance.

- Many researchers' did not establish the influence of the organizational culture on the decisionmaking process for which the researcher highly thought that there was an inter-linkage. Furthermore, for the research that was conducted to address these gaps, we found it useful to study the selected topic as a systemic issue in a holistic manner using a sound and balanced theoretical framework and empirical data.

\section{Methodology}

Research Design: The objective of this study was to understand the inefficiency in the public sector of the Republic of Congo. To achieve this objective, the design chosen was descriptive research which is a qualitative methodology of research that attempts to collect quantifiable information to be used for statistical analysis of a population sample. In that case, surveys can be used for recording; describing, interpreting and analysing facts that exist or either existed. Among others, these facts, can be assimilated but not limited to the trends that are developing, ongoing processes, effects that are evident or opinion that is expressed. However, surveys are primarily well- adapted with the existing. According to Gill et al. (2008:291), 'There are a variety of methods of data collection in qualitative research, including observations, textual or visual analysis (e.g. 
from books or videos) and interviews (individual or group). Also, focus groups which are one of the methods used in healthcare research.' The methods used to collect the quantifiable information for this research was individual interviews conducted.

Based on the questionnaires predefined for the purpose (Awolusi, 2012; Awolusi \& Akinruwa, 2013). We selected interviews among other data collection methods used for the descriptive research because, interviews helps to explore the experiences, beliefs, views or motivations of the respondents on specific matters. Furthermore, Gill et al. (2008:291) stressed that most of the researchers prefer to use interviews rather than sample quantitative methods like questionnaires. Interviews are mostly believed to provide a "deeper" understanding of the social phenomenon. Therefore, interviews were appropriate for this research because we wanted to get more detailed insights from the practitioners. In the other hand, we foresee that the research might have revealed sensitive topics that the respondents might not want to discuss in the group setup. Hence the choice made on the interviews methods which were appropriate and can explore sensitive topics.

The primary sources of data for this study were the public administration in the Republic of Congo, particularly the employees of Makelekele Town Hall. The Barcelona-based online software for online form building and online surveys (Typeform) was used by the researcher to digitalize data collected from the sampled respondents that thereafter were analysed. According to Vox TV (2017), the Minister of Public services and the reform of the State revealed on 22 ${ }^{\text {nd }}$ March 2017 during the session of the Cabinet held in Brazzaville that some 66,422 individuals were censuses as practitioners of the public services in the Republic of Congo. The statistics were obtained after the completion of the census exercise of the practitioners of the public services launched on $31^{\text {st }}$ October 2016. At the end of the exercise, the state counted 39,300 practitioners that represent $59.14 \%$ of the manpower of the public services employed in the capital Brazzaville, against 8,457 (12,73\%) employed in Pointe-Noire. In the upcountry, the number is relatively less given the fact that everyone wants to be employed in the two mains towns of the Country. Thus, 1,511 practitioners were censuses in Kouilou, 2,321 in Cuvette. In Cuvette-West, there were 1,088 practitioners and 1,129 in Sangha or 741 in Likouala. A little more of them 3,520 practitioners were counted in Niari, and 1,005 in Lekoumou. The departments of the Plateaux, Bouenza and Pool respectively count 1,702, 2,656, and 2,581 practitioners. The diplomatic representation of the Republic of Congo abroad counts in a total of 411 practitioners.

However, the number revealed by the Minister is not exhaustive since a huge number of these practitioners of the public services claimed that they were not censuses. Furthermore, because of the very limited time, distribution of the practitioners around the country, and shortage of money the researcher was limited to the capital Brazzaville that represent $59.14 \%$ of the total number of the practitioners reached by the census conducted by the state in 2016. In the capital city Brazzaville, the researcher limited his study to the eight services of Makelekele Town Hall of Arrondissement 1 were a total of 330 practitioners were engaged at the time of this research. To determine the sample for the survey, a scientific approach was used that indicate the appropriate size of the random sample for a given number of the wider population (Cohen et al., 2005:94). In fact, since the universe that constitutes a sample is not always a homogeneous group. In the aim of obtaining a representative sample, we applied a stratified sampling technique. Furthermore, to determine the sample size that represents the number of the respondents that were interviewed out the wider population, Yemane (1967) uses the following three variables. $\mathbf{N}$ as the sample size, $\mathbf{n}$ the estimated population and $\mathbf{e}$ the confidence level $(0.05)$. This implies that: $\mathbf{N}=\mathbf{n} / \mathbf{1}+\mathbf{n}\left(\mathbf{e}^{*} \mathbf{e}\right)$. Considering the total number of the practitioners of Makelekele Town Hall which was 330 at the time of the research. By using Yemane (1967) scientific formula, the researcher considered a total of 180 practitioners as the sample size for this research. Indeed, to come up with the above figure, the calculation was as follow: $\mathrm{N}=330 /\left(1+330^{*}\left(0.05^{*} 0.05\right)\right)$.

Data Collection and Analysis: During the process of data collection, three options were available to measure the factors that affect the employee's performance. They were a holistic approach, the metaphorical (language) approach, and the quantitative approach (Cameron \& Quinn, 2006). A quantitative approach requires the use of questionnaires or interviews to assess or understand facts. In this research, we used questionnaires to reach as much as a possible number of respondents. This was a descriptive survey. We believe that it gave enough time to the respondent to provide well-articulated answers and also reduce the 
cost to the researcher. There are different types of reliability and validity. Moreover, as highlighted by (Cohen et al., 2005) there are several ways in which they can be addressed. In simple term, validity refers to a degree to which an instrument subjectively measures what it is intended to measure. In other words, validity is when an instrument appears to do what it claims to supposed to do. In the case of this research, for example, validity focused to achieve the purpose of this study.

Moreover, (Burton \& Mazerolle, 2011) stated that four procedures exist in establishing the validity of an instrument. However, given that they present few difficulties to ascertain, face and content are qualitative measures of validity often used in survey research. In the other hand, (Burton \& Mazerolle, 2011:28) further stressed that to secure face and content validity, there is need to submit the instrument for review by a panel of experts comprised of individuals that have an expertise in the field that the instrument will measure. The panel of experts will look into the survey's relevance, appearance and representativeness of its elements. For this research, the face and content were secured after submitting the instrument to five colleagues from the researcher's workplace that are well-versed in human resources and employee's performance management field. Some minor changes to 10 out of the 25 questions content and face were suggested. After three rounds of exchange with the colleagues, the instrument was approved for face and content validity.

According to (Cohen et al., 2005), reliability is essentially a synonym for consistency and replicability over time, over instruments and groups of respondents. For this research to be reliable there was needed to ensure that the measurements that were used for the validity were consistent with other researches conducted on the impact of the managerial decisions on employee's performance. According to (Villasís et al., 2018), validity in research is a concept that refers to what is true or closes to the truth. They further stated that the result of the investigation is considered to be valid when the study is free of errors. These errors or biases are generally due to the research methodological problem. Moreover, Messick (1980) stressed that in all research, the phenomena being researched must be accurately described through the findings, but if this does not happen then the level of validity is questioned. The researcher focused the questionnaires on the most realistic way of investigating the phenomena being researched. The questionnaires were constituted of balanced closed-ended and open-ended questions. In this way, the researcher anticipated having a more holistic view of the respondents on the phenomena being investigated. The questionnaires were submitted to the validation of the researcher's assessor before conducting interviews with employees of different services of Makelekele Town Hall.

Methods of Data Analysis: The data obtained from the individual's interviews were analysed using SPSS (Statistical Package for Social Sciences) software. Although (Lewis, 2004) highlighted that NVIVO and ATLAS.ti are amongst the best available qualitative data analysis tools. Reason being that, the two products allow the researcher to associate codes or labels with texts. Moreover, they are designed to support the use of several types of data like sounds, pictures or video. These products are flexible and can be easily used in a wide range of applications. Also, the two products are compatible with Microsoft Windows operating system. However, the fact that motivated our choice to use SPSS instead of NVIVO or ATLAS.ti is that ATLAS.ti work with a very limited range of data files types e.g. text files have to be converted in ASCII or ANSI before uploading them in the software while NVIVO focus in analysing non-numerical or unstructured data. Or, SPSS is used for statistical analysis of data and provide analytical reporting which was more appropriate for this research.

\section{Results and Discussion of Findings}

Demographic Analysis: The researcher focused his study in the following services "affaires foncières, législation, agriculture \& élevage, domaine public de l'état, état civil, instruction civique, jeunesse, and secretariat general" of Makelekele Town Hall. In order to gather the information that was analysed, two hundred and fifty (250) forms of the interview questionnaires were distributed in the different services listed above. Out of the total number of two hundred and fifty (250) interview questionnaires forms distributed, $180(90 \%)$ that were properly filled and returned were compiled. Table 1 shows the characteristics of the respondents. 
Table 1: Characteristics of the Respondents Disaggregated by Age Range

\begin{tabular}{lll}
\hline Age Range of the Respondents & Number Reached & Percentage (\%) \\
\hline $20-25$ & 0 & 0 \\
$26-30$ & 10 & 6 \\
$31-35$ & 10 & 6 \\
$36-40$ & 40 & 22 \\
$41-45$ & 20 & 11 \\
$46-50$ & 30 & 17 \\
$51-55$ & 20 & 11 \\
$56-60$ & 50 & 28 \\
Not provided & 0 & 0 \\
Total & $\mathbf{1 8 0}$ & $\mathbf{1 0 0}$ \\
\hline
\end{tabular}

The data presented in the above Table 1 shows that $28 \%$ of the respondents reached were between the ages $56-60.22 \%$ of the respondents were between the ages of $36-40.17 \%$ of the respondents were between the ages $46-50$ and $11 \%$ of the respondents fall in the age range $41-45$ years and $51-55$ years while the youngest employees represent only $6 \%$. It is worth noting that, the percentage of the respondents in the age higher than or equal to 36 years old increases as the age increases. This is an indication showing that there are fewer juniors among the employees of Makelekele Town Hall. Overall, all the respondents indicated their age hence $0 \%$ represents the number of the respondents that did not indicate their age.

Table 2: Characteristics of the Respondents Disaggregated by Sex

\begin{tabular}{lll}
\hline Sex of the Respondents & Number Reached & Percentage (\%) \\
\hline Female & 80 & 44.4 \\
Male & 90 & 50.0 \\
Not provided & 10 & 5.6 \\
Total & $\mathbf{1 8 0}$ & $\mathbf{1 0 0}$ \\
\hline
\end{tabular}

The data presented in the above Table 2 shows that $50 \%$ of the respondents were male and $44.4 \%$ were female. However, 5.6\% did not indicate their sex. According to (Senn \& Childress, 2000), being able to deal with the many issues of diversity is fundamental to organizational performance. In that case, most probably the result of the study could have been different if the number of female working at Makelekele Town Hall has been more than the current. Indeed, employees differ based on their gender, age, and ethnic background.

Table 3: Characteristics of the Respondents Disaggregated by Years of Experience

\begin{tabular}{lll}
\hline Years of experience & Number reached & Percentage (\%) \\
\hline 1-2 years & 20 & 11 \\
3-4 years & 10 & 6 \\
5-6 years & 50 & 28 \\
7-8 years & 30 & 17 \\
$9-10$ years & 10 & 6 \\
More than 11 years & 40 & 22 \\
Not provided & 20 & 11 \\
Total & $\mathbf{1 8 0}$ & $\mathbf{1 0 0}$ \\
\hline
\end{tabular}

The data presented in the above Table 3 shows that $28 \%$ of the respondents have been working at the Town Hall since 5-6 years. 22\% of the respondents are working for more than 11 years. $17 \%$ are working since seven (7) to eight (8) years. The percentage of employees with more years of experience is higher than the younger generation while $11 \%$ did not provide their seniority.

Analysis and Interpretation of Data Gathered: The Town Hall is a structure operating under the public sector which is a very dynamic environment in terms of services provided to the general public. Although we 
assume that challenges might exist from the central government in terms of budget to improve working conditions and quality of services. For the Town Hall to ensure that the services provided to the general public are of good quality there is need to conduct a frequent assessment of the quality of services provided to the general public versus employee's training and performance. Moreover, Mpofu \& Hlatywayo (2015) stated that to improve employee's performance and organizational growth, organizations have identified training and development of the employee as one of the critical aspects. Indeed, the Town Hall will not aim for growth because it is operating in the public sector but employee's performance will still have a significant impact on the services provided to the general public.

Considering the findings of the research, twenty-two percent $22.2 \%)$ of the respondents reached indicated that they are not adequately trained to perform their work. Taking into consideration the number of respondents reached, we assume that this represents the reality in most of the structures in the public sector within the Country whereby employees are not adequately trained to carry out their duties. In the other hand, twenty height percent $(27.7 \%)$ of the respondents reached indicated that 10 to 15 years was the number of years that have elapsed since the time they were last trained and or they last attended a refresher training. These have to be considered among the factors which likely affect the performance of the practitioners in the public sector. The following present more details on the analysis of the findings for the below two questions.

Table 4: Do you feel you are adequately trained to perform your Job?

\begin{tabular}{llllll}
\hline & & Frequency & Percent & Valid Percent & Cumulative Percent \\
\hline \multirow{2}{*}{ Valid } & Yes & 110 & 61.1 & 73.3 & 73.3 \\
& No & 40 & 22.2 & 26.6 & \\
Missing & Total & 150 & 38.3 & 100.0 & 100.0 \\
Total & System & 30 & 16.6 & & \\
\hline
\end{tabular}

$61.1 \%$ of the respondents have been adequately trained and 110 feel they are adequately equipped however $22.2 \%$ of the respondents are not adequately trained.

Figure 2: Employee's View about the Capability

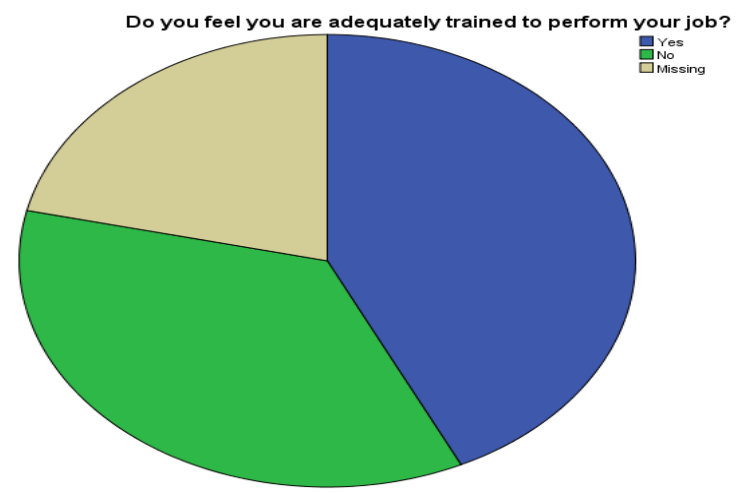

Table 5: What was the Last Time (Year) you attended Refresher Training?

\begin{tabular}{llllll}
\hline & & Frequency & Percent & Valid Percent & Cumulative Percent \\
\hline & last 5 years & 60 & 33.3 & 50.0 & 50.0 \\
& 6-10 years & 10 & 5.5 & 8.3 & 58.3 \\
Valid & 10-15 Years & 50 & 27.7 & 41.6 & 100.0 \\
& 6.00 & 0 & 0.0 & 0.0 & 100.0 \\
& Total & 120 & 66.6 & 100.0 & \\
Missing & System & 60 & 33.3 & & \\
Total & & 180 & 100.0 & & \\
\hline
\end{tabular}

$27.7 \%$ of the respondents have not received any pieces of training for the last $10-15$ years 
Figure 3: Employee's View about Training Attendance

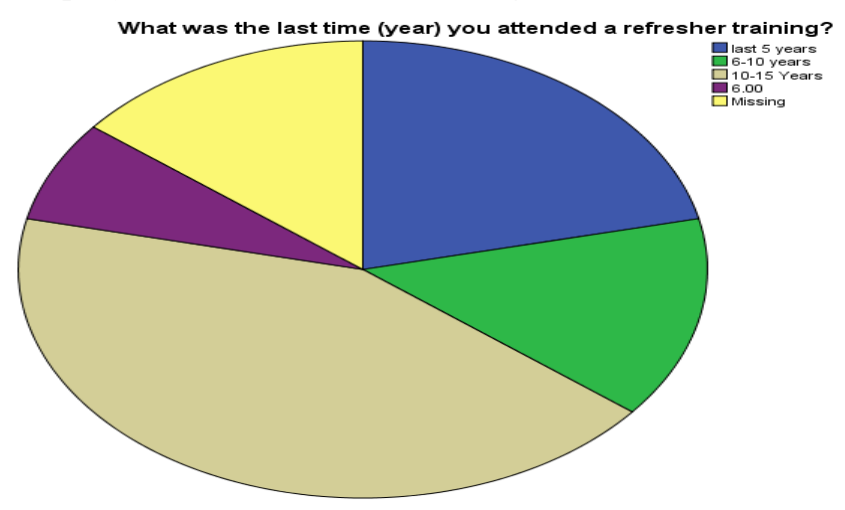

In the other hand, eleven percent (11.1\%) of the respondents reached indicated that they were not sure whether the top managers have the required managerial skills to make the decisions that impact employee's performance. In the meantime, ninety-three percent (93.7\%) of the respondents indicated that decisions taken by top managers can have an impact on their performance. In this case, for the Town Hall in particular and the public sector, in general, to provide quality services to the general public, there is need to have employees qualified in their field and this is possible only with the employee's capacity building plan in place. Moreover, (Frauk, 2018) further stressed that where there is ineffective management, to improve employee's performance, the support from qualified and competent employees in their field is required. On the same note, employee's coaching is key in being considered and prioritized as main assets in the company. Furthermore, for the employees' skills to be improved and or maintained, the capacity building plan must be a culture within the public sector.

In this case, there is a need to consider critically the loyalty and retention of those competent employees. Therefore, the State should look at this very important approach which consists in the development of human resources in the different department of the public sector. Hence we can assume that employee's performance is also affected by the leadership, education and training. The following present more details on the analysis of the findings for the below two questions.

Table 6: Do you think that the Decision Taken by the Top Management can have an Impact on your Performance?

\begin{tabular}{llllllc}
\hline & & Frequency & Percent & Valid Percent & Cumulative Percent \\
\hline \multirow{4}{*}{ Valid } & Strongly Agree & 50 & 27.7 & 31.2 & 31.2 & \\
& Agree & 100 & 55.5 & 62.5 & 93.7 & 6.2 \\
& Strongly Disagree & 10 & 5.5 & 6.2 & & \\
& Total & 160 & 88.8 & 100.0 & 100.0 & \\
Missing & System & 20 & 11.1 & & & \\
Total & & 180 & 100.0 & & & \\
\hline
\end{tabular}

Figure 4: Employee's View about Decision Making

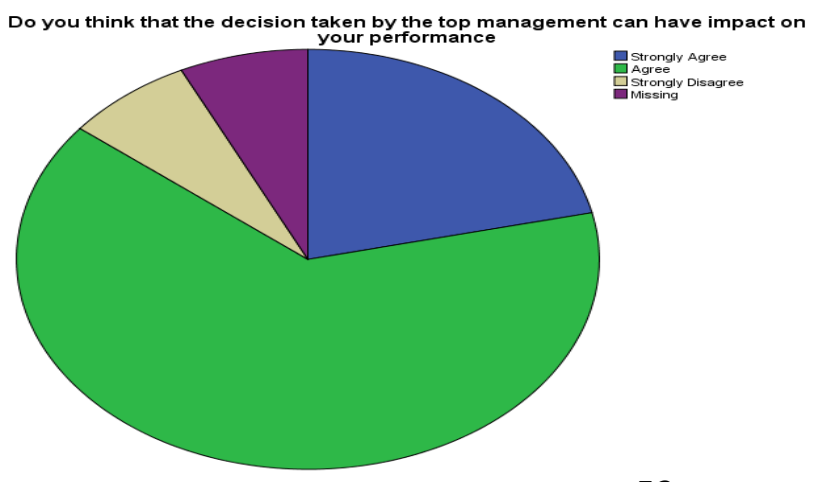


Table 7: Do Top Managers have the Required Managerial Skills to Make the Decisions that Impact the Performance of the Employees?

\begin{tabular}{llllll}
\hline & & Frequency & Percent & Valid Percent & Cumulative Percent \\
\hline & Strongly Agree & 30 & 16.6 & 30.0 & 30.0 \\
& Agree & 50 & 27.7 & 50.0 & 80.0 \\
Valid & Disagree & 0 & 0.0 & 0.0 & 0.0 \\
& Not sure & 20 & 11.1 & 20.0 & 20.0 \\
& Total & 100 & 55.5 & 100.0 & 100.0 \\
Missing & System & 80 & 44.4 & & \\
Total & & 180 & 100.0 & & \\
\hline
\end{tabular}

Figure 5: Employee's View about the Top Manager's Managerial Skills

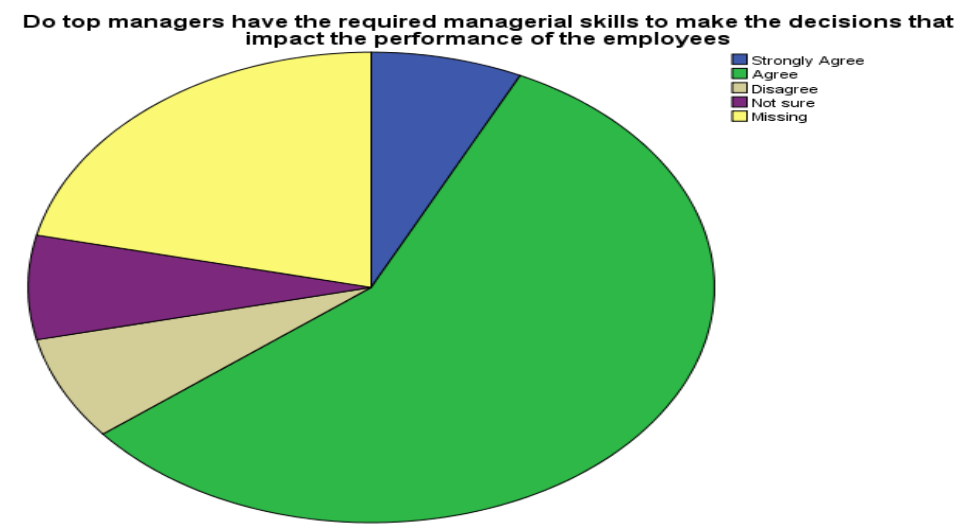

Further to the above, it is worth noting that, the respondents reached revealed other relevant findings for the researcher. Thirty-eight percent (38.8\%) of the respondents indicated that their managers never promote career development. In the other hand, forty-four percent (44.4\%) of the respondents further indicated that the top management was not undertaking performance management appraisal for the employees. We assume that all these factors put together are enough to impede the employee's performance which affects significantly creative behaviour. Moreover, Ismail and Rishani (2018) highlighted that creative behaviour is related to career development and performance appraisal satisfaction. Ismail and Rishani (2018) further stressed that organizations that fail to build effective career development systems at work will likely not be able to guarantee employee creativity despite the satisfaction that the performance appraisal can produce to the employee. In the case of the Town Hall in particular and the public sector in general, the top managers don't promote the culture that uses the two variables (career development and performance management appraisal) hence making it difficult for the employee to develop a creative behaviour leading to a negative impact on the employee's performance. The following present more details on the analysis of the findings for the below two questions.

Table 8: How often does your Employer Promote Career Development?

\begin{tabular}{llllll}
\hline & & Frequency & Percent & Valid Percent & Cumulative Percent \\
\hline \multirow{3}{*}{ Valid } & Sometimes & 80 & 44.4 & 53.3 & 53.3 \\
& Never & 70 & 38.8 & 46.6 & 100.0 \\
& Total & 150 & 83.3 & 100.0 & \\
Missing & System & 30 & 16.6 & & \\
Total & & 180 & 100.0 & & \\
\hline
\end{tabular}

$38.8 \%$ believe that employer doesn't promote career development. 
Figure 6: Employee's View about the Manager's Willingness to Promote Career Development

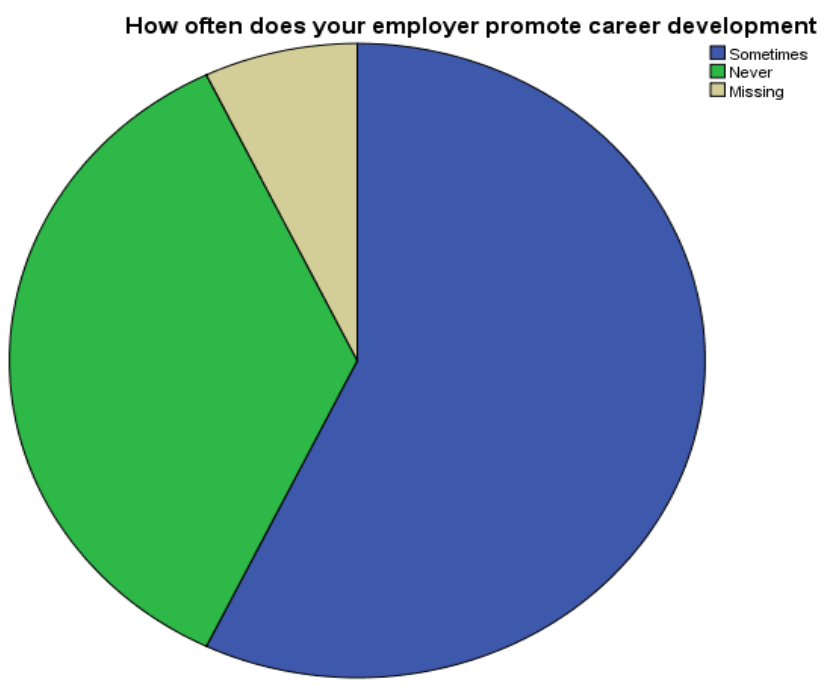

Table 9: Is the Top Management Undertaking Performance Appraisal for the Employee?

\begin{tabular}{llllll}
\hline & & Frequency & Percent & Valid Percent & Cumulative Percent \\
\hline \multirow{3}{*}{ Valid } & Yes & 70 & 38.8 & 46.6 & 46.6 \\
& No & 80 & 44.4 & 53.3 & 100.0 \\
Missing & Total & 150 & 83.3 & 100.0 & \\
Total & System & 30 & 16.6 & & \\
\hline
\end{tabular}

$44.4 \%$ of top management don't perform management appraisal.

Indeed, Conny et al. (2015) in their research conducted on employee's retention and motivation it was revealed that financial and non-financial reward can improve individual, team performance and organizations effectiveness. Furthermore, the researcher observed that twenty-eight percent (28\%) of the respondents reached rated the services provided to the general public at two (2) on Likert scale (one (1) to five (5)) while in the meantime, $61.6 \%$ of the respondents were comfortable with the services provided to the general public.

Figure 7: Employee's View about Performance Management Appraisal

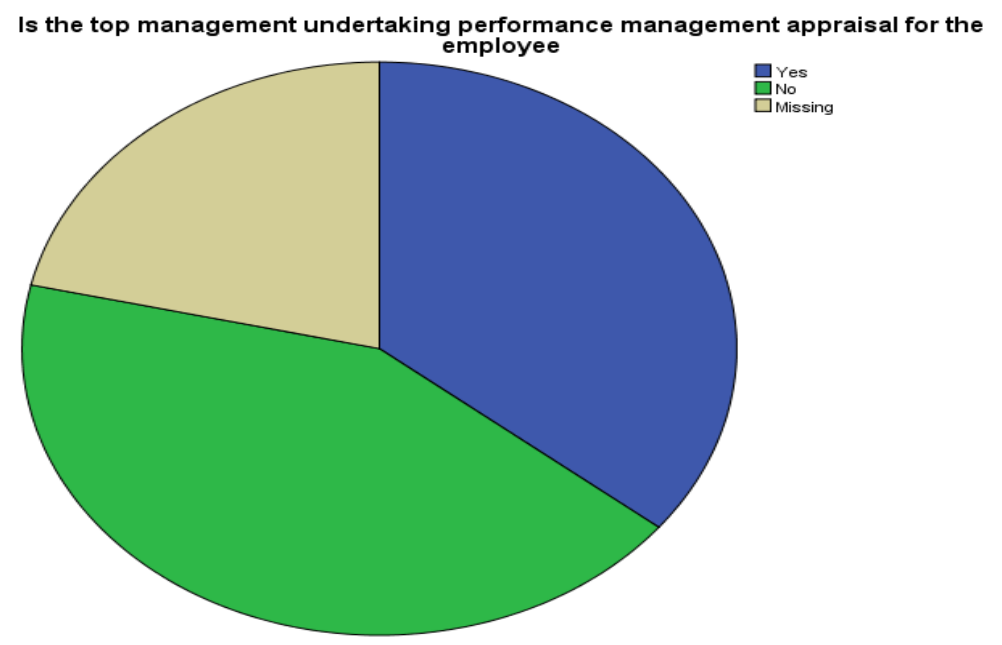

Finally, ninety percent (90\%) of the respondents also indicated the fact that they are rarely rewarded in the accomplishment of their duty. This is another factor that can affect significantly the employee's performance 
in the Town Hall in particular and in the public sector in general. This might imply that, either the employee's performance has a direct impact on the quality of services rendered to the general public or the employees doesn't have appropriate tools to carry out their work at the Town Hall in particular or in the public sector in general. In the other hand, during the data collection process, the researcher observed also the fact that the working environment at the Town Hall doesn't offer good working conditions. Indeed, this has a significant impact on the employee's performance. The employees were squeezed in the small offices that missed minimum basic equipment such as electronic equipment for air conditioner or information management technology equipment to carry out their work namely computers and printers. Moreover, Raziq \& Maulabakhsh (2015) stressed that the bad working environment prevents the employees to develop their full capabilities and attain their potential. Also, to meet the organization's standards while developing their full capacity, employees need good working conditions which correlate with job satisfaction, hence increasing employee's productivity and performance. The following present more details on the analysis of the findings for the below two questions.

Table 10: If Yes, How often have you been rewarded?

\begin{tabular}{llllll}
\hline & & Frequency & Percent & Valid Percent & Cumulative Percent \\
\hline \multirow{4}{*}{ Valid } & Usually & 20 & 11.1 & 20.0 & 20.0 \\
& Sometimes & 20 & 11.1 & 20.0 & 40.0 \\
& Rarely & 50 & 27.8 & 50.0 & 90.0 \\
& Never & 10 & 5.6 & 10.0 & 100.0 \\
Missing & Total & 100 & 55.5 & 100.0 & \\
Total & System & 80 & 44.4 & & \\
\hline
\end{tabular}

Figure 8: Employee's View about Reward

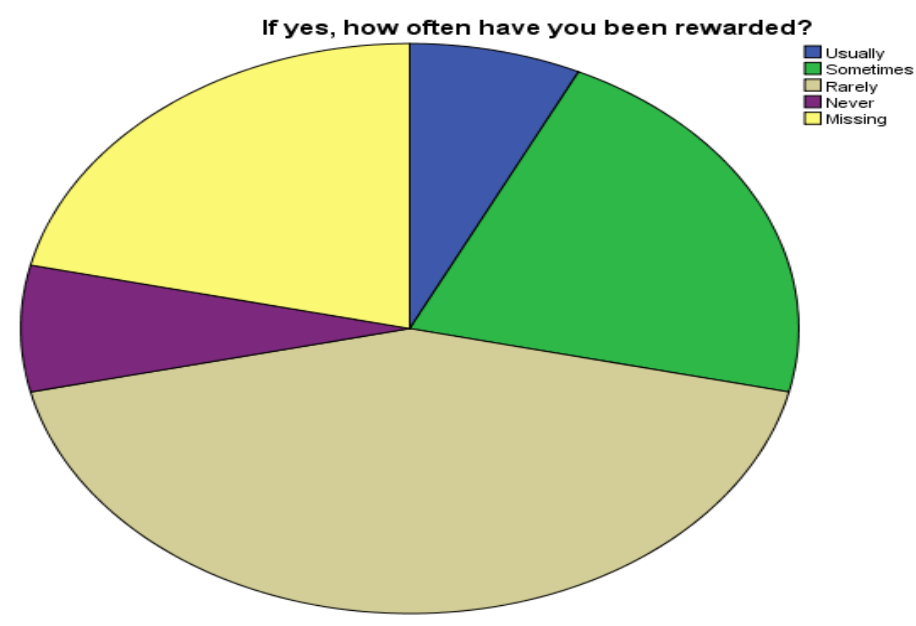

Table11: Do you think that the Services provided to the General Public are of a High Standard?

\begin{tabular}{llllll}
\hline & & Frequency & Percent & Valid Percent & Cumulative Percent \\
\hline \multirow{3}{*}{ Valid } & Yes & 110 & 61.1 & 84.6 & 84.6 \\
& No & 20 & 11.1 & 15.4 & 100.0 \\
Missing & Total & 130 & 72.2 & 100.0 & \\
Total & System & 50 & 27.7 & & \\
\hline
\end{tabular}

$61.6 \%$ of the respondents are comfortable with the services of the public sector to the general public 
Figure 9: Employee's View about Services provided to the General Public

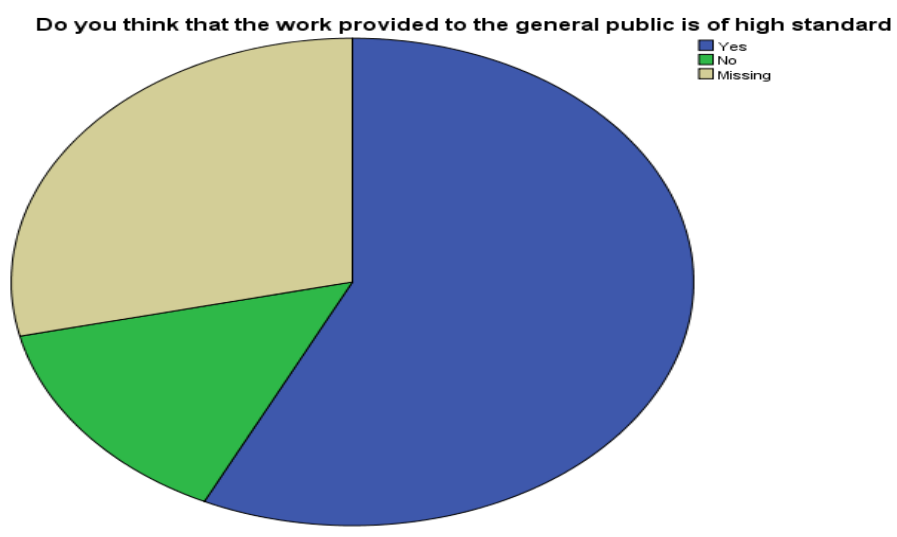

Management of Employee's: The answers provided by the employees for the question related to "whether employee's opinions were taken into consideration while attending managerial meetings" shows that most of the respondents reached (over 70\%) do participate in the managerial meetings and in those forums their opinions were taken into consideration. Indeed, this is a good employee's decision approaching employee's management which value and put the employees in the centre of the Town Hall management. Given that this approach can have a positive impact on the employee's performance, the researcher thinks that it will be good if this approach can be perpetuated. Another good practice, that the researcher observed is the use of a competitive recruitment process and promotion in the process of appointing employees on the higher grades. Although, questions on career development and performance appraisal were asked to the respondents. However, due to its sensitivity, the researcher was not able to capture which topics were usually discussed during these managerial meetings that they attended. Ideally, questions of general interest should be discussed in such meetings; conclusions and actions points must be drawn for further follow-up.

Employee's Perception: According to their perception, the respondents reached indicated the following: they are not adequately trained moreover the number of years that have elapsed since the last time (year) the majority of them were trained or attended a refresher training was 12-10 years yet they feel adequately trained to perform their duties. This is a complex situation that the management of the Town Hall should be aware of to find out how to address the issue; for those who were not rewarded in the accomplishment of their duties, the respondents indicated that it is their salary and or the desire to serve that motivate them to enjoy their jobs and current work situation. The employees indicated also that, the salary scale, the need of employee's capacity building training and the improvement of the working conditions are the three things if they were supposed to should be changed to improve employee's performance at work. In the other hand, employees think that the decisions taken by the top management can have an impact on their performance. However, in the meantime, they also indicated that the top management doesn't have the required managerial skills to make the decisions that impact the performance of the employees.

Discussion of Findings: The study has reinforced what is already known on the topic. First of all, as highlighted by Trip et al. (2002) the ability of the managers is critical in the employee's efficiency and among the factors that affect the employee's performance the respondents indicated that managerial decisions have an impact on their performance. The researcher assumes that this is logical taking into consideration phenomenon such as the Pygmalion effect. Secondly, as stated in the results of the study conducted by Bercu (2013) it was also observed during the study that there is a difference in the decision making in the public sector in contrast to the private sector. Indeed, in the private sector, the decisions made follows clear established and logical procedures. The respondents that were sampled highlighted the dependency that exists in the public sector in regards to the political decisions which are mostly based on the balance of influence. Furthermore, it was revealed that the issues related to efficiency and effectiveness discussed in the research conducted by Bercu (2013) were not the cardinal values in the public sector. Moreover, the respondents sampled indicated that the top management was not undertaking performance appraisal and neither promoting career development which is among the things that need to be considered for employee's efficiency and effectiveness. 
As highlighted by Gill et al. (2014) in their study the impact of the decision taken by the top management on the group whereby the top management needs to create an environment that facilitates the work of the employees were also indicated by the respondents sampled. In the sense that, they indicated their involvement and their participation in the managerial meetings where their opinions are considered and valued. This explains how the top management at the level of the structure of the public sector strives to create an environment where the common purpose lead. In the other hand, in the course of this study, the researcher identified a fact that was not discussed before that need to be considered for further studies. The relation between the organizational culture and the decisions taken by the top management that have a significant impact on employee's performance. Indeed, depending on its organizational culture the way the decisions are taken differ from one organization to another mostly impact directly employee's performance knowing that the top managers are considered as a mentor and they are supposed to lead with a common purpose. This was observed in the public sector which is more of a power culture organization. Further studies on this fact will reveal more findings as to which extend the organizational culture impact the employee's performance.

\section{Summary, Conclusion and Policy Recommendations}

Summary: This study aimed to understand the root cause of the inefficiency in the public sector in the Republic of Congo. The researcher focused was to answer the following research questions: Does the management undertaking performance management appraisal for the practitioners of the public sector in the Republic of Congo? Do the practitioners of the public sector feel the difference made by their work on the general public? Do the practitioners of the public sector being rewarded in their work? What motivates the most the practitioners of the public sector for them to report every day at work? Does the management promote career development for practitioners of the public sector in the Republic of Congo? How does the management ensure that the skills of the practitioners of the public sector in the Republic of Congo remain up to date to allow them to perform their daily work? In summary, the findings of the study show that there are practices in the public sector that need to be reviewed to improve the performance of the employees.

Furthermore, the respondents reached indicated that they were not rewarded on their job (33\%) while 11\% did not provide answers to the question. The Likert scale was used to evaluate the quality of the services provided to the general public. In the course of the study, the findings were that $28 \%$ falls under 2 on the scale while $22 \%$ falls under 3 with $30 \%$ of the respondents that did not provide their answers. On the question related to the motivation to report every day at work, while the employees are not rewarded being in financial or non-financial aspect such as through promotion or career development, $17 \%$ of the respondents reached indicated that the desire to serve as the only motivation in this case. The question related to how the management ensures that the skills of the employees remain up to date to allow them to perform their daily work, recorded $28 \%$ of the respondents that the number of years that have elapsed since they were last trained is 10 to 15 years while $33 \%$ of the respondents did not provide answers on the question.

Conclusion: In the course of this study, the researcher tried to understand the root cause of the inefficiency in the public sector in the Republic of Congo while focusing on the case study of the factors that affect the performance of the employees in MakeleKele Town Wall. The respondents reached believes that the improvement of the working conditions, the revision of the salary scale and the need for capacity building training for the employees are things that need to be changed to improve employee's performance at work. In this case, there is a need for goal-oriented managers. Indeed, if the employees are valued most likely they will perform efficiently and effectively. Hence improving their performance at work. Finally, employees do attend the managerial meetings as indicated by the respondents reached.

Almost all the respondents reached further highlighted that their opinions or inputs were taken into consideration in the meetings they attended. But looking at the findings of the study, issues about capacity building, performance appraisal, and career development systems are the main issues that the top management will need to put on the top of the agenda while addressing the factors that affect the performance of its employees. In light of the study conducted, the researcher has observed several aspects which are not part of Makelekele Town Hall or the public sector culture which most likely affect the 
performance of the employees at work. Indeed, to improve the employee's performance at work there is a lot that needs to be done in terms of capacity building, career development, improvement of working conditions, reward, employee's periodical performance appraisal, and the recruitment process.

Recommendations: It is worth noting that, most of the structures of the public sector in the Republic of Congo are not autonomous and their daily management depends directly on the Ministers that they are linked to. For example, the Town Hall is under the management of the Minister of Interior and decentralization. Hence to achieve the culture that takes into consideration the aspects mentioned above there is a need to review the entire management of the public sector in the Republic of Congo. The Ministers from the central government could make things to happen if they work in making the structure under their management to become more autonomous. This is possible by involving the employees in all the phases of strategic planning. First and foremost, the top management in the public sector should put in place a team of employees that will be in charge to set but also they will be monitoring and reporting periodically on the standards of all aspects related to the working conditions and the employee development. By doing so, the top management will promote the culture of excellence in the workplace while serving as a model.

Of course, while the top management has to serve as a model at the workplace they have to also instil the sense of belonging in their employees. Moreover, this will enables the employees to find meaning in their work. Indeed, the top managers have the responsibility to make their employees fill more than happy not only about doing their job but doing it while having a sense of belonging. This can include but not limited to incentives, or low-interest loan. The researcher assumes that this will build in the employees the character of carrying about the organizations that they belong and work for. In all the actions that will be taken in the aim to improve employee's performance, there is a need for team unity. However, for the momentum that will be created by the central government to have an impact on employee's performance, the top managers in different structures should work in introducing competition among their team members in that way employee will be motivated to demonstrate a great team spirit among themselves.

Moreover, the researcher assumes that it is when the team members see a sign of competition that is when team unity tends to be strengthened. The improvement of employee's performance is conditioned also by the improvement of working conditions. The central government should work first in improving working conditions in the different structures of the public sector before to expect the improvement of employee's performance. This can be done a multi-year plan. The improvement of working conditions should consist of the renovation of the buildings, allocation of equipment like desktops, printers and also Internet connection in these structures. Thereafter, the top management can design an employee's development plan for the entire public sector which will include recruitment process, a series of training for capacity building, establish a performance appraisal and career development system, a reward system, and define clear conditions that need to be fulfilled for employee's promotion to a higher grade. Following are the suggestions on how the researcher think these systems can be established and also managed.

Recruitment Process: The researcher recommends that the recruitments for all categories of employment should be fair and competitive. The central government can re-introduce an entrance to the public sector examination for all categories of employment: executive manager, middle manager and employee. By introducing this approach, the public sector will somehow have qualified personnel for each of its structures.

Training for Capacity Building: The researcher recommends that together with the employees the top management should adopt an employee's decision-making approach by involving the employee in the decision making. Therefore, to come up with the catalogue of training that will be proposed for employee's capacity building, the top management together with the employees should assess the needs and decide on the type of training that will be proposed. The priority can be given to the junior employees as we assume that with the competitive recruitment process, most of the executive and middle managers will have had required training and competences in their fields. Once the internet connection has been installed in these structures of the public sector, the top management should be envisaged as soon as possible, to design an Elearning platform for the public sector to promote employee's self-study and reduce the cost of housing workshops which can be organized on need basis. In the other hand, the option of organizing webinars or video-conference can also be adopted in the aim of reducing the cost of the capacity building while in the 
meantime improving the employee's performance. In this way, employees will remain competitive with their performance at work improved continuously.

Performance Appraisal and Career Development System: The researcher recommends that an annual performance management appraisal system comprised of three phases should be introduced for all categories of employment in the public sector. An effective performance management system tends to strengthen employees understanding of their performance, potential and contributions within the organization. This will also establish a framework of accountability for employees vis a vis their duties. Indeed, UNHCR (2019) stressed that "It fosters not only performance excellence and career growth but also team and individual development and learning. Moreover, poor performance management lowers morale, decreases productivity, and negatively impacts on the potential of individuals and teams". The first phase: the start of the cycle will consist of supervisees and their supervisors to come up to an agreement on the work objectives to be achieved and the competencies to be demonstrated within the evaluation period; The second phase: Mid-year review will consist of supervisors and supervisees discussion on overall supervisee's performance and progress towards achieving the objectives and demonstrating the competencies agreed upon; The third phase: final evaluation will consist of the supervisee to initiate a self-evaluation and the supervisor will complete the evaluation based on the supervisee's self-evaluation.

Reward System: The researcher recommends a reward system to be established for the public sector. The criteria to become eligible for a reward can be discussed in the employee's decision-making forum (Ariff \& Karen, 2018). Nonetheless, the researcher suggests but not limited to rewards in form of recognition of services rendered certificate that can be issued to the employees, bonus for employees that perform to the successful completion of their duties, etc. It can be also a good idea to consider promotion to a higher grade as a reward for employees that demonstrate good performance management for several years. By doing so, the researcher assumes that the approach can improve an employee's performance and boost employees and team morale at work.

Promotion to a Higher Grade: The researcher recommends the top management to establish clear criteria that will be used for the employee's promotion to a higher grade. These can also be discussed in the employee's decision-making forum. The criteria can be for example but not limited to the qualification (academic background), number of years of experience, performance management, etc.

Contributions to the knowledge: As mentioned earlier, there were limited researches on the topic and this study was also limited to understanding the factors that affect the employee's performance. However, the researcher tried to provide answers to some of the weaknesses identified in these previous researches. First and foremost, the researcher reinforced the knowledge on the topic and established the correlation between managerial decision-making and employee's performance. Indeed, as perceived by the respondents that were sampled the decisions taken by the top management have a significant impact on the employee's performance. The researcher further explored the inter-linkage between the organizational culture and the decisions made by the top managers that have a direct impact on employee's performance.

It was revealed in the study that, the management of the public sector in the Republic of Congo is fully dependant of the different ministers who are managed by ministers from the central government. Hence, the organizational culture in its structures is more of power culture. The researcher further observed during the study that the decisions in the public sector are mostly taken on political grounds. Moreover, this reinforced what Handy (1993) highlighted the power culture in which environment the decisions are mostly taken based on a balance of influence not on well-established procedural or logical grounds. The researcher considers the information in this research paper as the basis for further researches on the factors that affect employee's performance in the public sector.

However, there were several limitations encountered during the present study such as access to the data that, the researcher intended to collect in the different services of Makelekele Town Hall. The analysis of the interview questionnaires shows that some employees were reluctant to share their true opinions. Even though, the researcher explained explicitly to the employees the ethical considerations of the research that only anonymous information was to be collected and all information collected were to be handled 
confidentially. The researcher was unable to analyse the open-ended questions given that most of these were not filled. Hence, the competing values and the sources of the decision making were not analysed in the course of this study. Nonetheless, no study has been conducted before in connection with this issue. This represents then an initial step to investigate the root cause of the inefficiency in the public sector. Therefore, now the public sector in the Republic of Congo can utilize the information in this research paper to improve the employee's performance and create the innovation culture in its several structures for the benefit of the population.

Acknowledgement: This paper is an extracts from a Master of Business Administration thesis at the University of Roehampton, London. Prof. Olawumi .D. Awolusi was the supervisor of the study.

\section{References}

Ariff, K. \& Karen, S. (2018). Decision-Making Models in the SAGE Encyclopedia of Business Ethics and Society (Ed.). Loyola University Chicago: Sage publications, Inc., 22-34.

Arinder, M. K. (2016). Bridging the divide between evidence and policy in the Public Sector Decision Making: A Practitioner's Perspective. Public Administration Review, 76(3), 394-398.

Awolusi, O. D. (2012). Effects of customer service management on business Performance in the Nigerian banking industry, International Journal of Data Analysis and Information Systems, 4(1), 23-36.

Awolusi, O. D. \& Akinruwa, T. E. (2013). Enterprise Resource Planning and Customer Service Management: an empirical study among Nigerian banks. International Journal of Advancement in Management Science, $3(3), 28-41$.

Bercu, A. M. (2013). Strategic Decision Making in Public Sector: Evidence and Implications. Acta Universitatis Danubius. Economica, 9(1), 21-27.

Blazi, C. \& Awolusi, O. D. (2020). Employee Engagement in Multinational Diverse Organization in Difficult Terrain: A Study of Non-Family Station Organization. Information Management and Business Review, 12(1), 45-62.

Bonavia, T. \& Brox-Ponce, J. (2018). Shame in decision making under risk conditions: Understanding the effect of transparency. PLOS ONE, 13(2), 191-990.

Burton, L. J. \& Mazerolle, S. M. (2011). Survey instrument validity part I: Principles of survey instrument development and validation in athletic training education research. Athletic Training Education Journal, 6(1), 27-35.

Cohen, L., Johanson, T. \& Cole, T. (2005). Research Methods in Education (5th Edition). London, UK: Taylor \& Francis e-Library.

Conny, H. A., Baeten, X., Perkins. J. S., \& Shaw, J. D. (2015). Reward management-Linking employee motivation and organizational performance. Journal of Personnel Psychology, 14(3), 163-164-60.

Dobel, J. P. (1990). Integrity in the Public Service. Public Administration Review, 50, 356-366.

Drafke, M. (2008). The Human Side of Organizations (9th ed.). New Delhi, India: Prentice-Hall of India.

Frauk, U. (2018). The Effect of Education and Training to Employee Performance Through Leadership as Intervening Variables at PT. Hutama Agung Jakarta Indonesia. International Journal of Business and Applied Social Science, 4(2), 71-87.

Gildas, M. (2018). Research Methods. Developing your management inquiry skills. University of Roehampton Online Programmes. August 6th Term, 2018.

Gill, R. H., Abcons, H.T. \& Jones, T.D. (2014). The power of invisible leadership: How a compelling common purpose inspires exceptional leadership. Thousand Oaks: Sage publications, Inc.

Gill, P., Stewart, K., Treasure, E. \& Chadwick, B. (2008). Methods of data collection in qualitative research: interviews and focus groups. British Dental Journal, 204(6), 1-295.

Grant, R. M. (2005). Contemporary strategy analysis. Boston, MA: Blackwell Publishers.

Handy, C. (1993). On the Cultures of Organizations', in Understanding Organizations, 4th edition, Oxford: Oxford University Press, 183-191.

Hejka-Ekins, G.H. (1988). Teaching Ethics in Public Administration. Public Administration Review, 47 (September/October), 885-891.

Hwabamungu, B., Brown, J. I., \& Willians, R. Q. (2018). Stakeholder influence in public sector information systems strategy implementation-The case of public hospitals in South Africa. International Journal of Medical Informatics, 109(1), 38-48. 
Ismail, H. N. \& Rishani, M. (2018). The relationships among performance appraisal satisfaction, career development and creative behaviour. The Journal of Developing Areas, 52(3), 109-124.

Jönsson, S. \& Lukka, K. (2005). Doing interventionist research in management accounting. Gothenburg: Gothenburg Research Institute.

Kozlenkova, I. V., Samaha, S.A., \& Palmatier, R.W. (2014). Resource-based theory in marketing. Journal of the Academy of Marketing Science, 42(1), 1-21.

Lee, S. Y. \& Whitford, A. B. (2013). Assessing the effects of organizational resources on public agency performance: Evidence from the US federal government. Journal of Public Administration, 23(3), 687-712.

Lewis, R. B. (2004). NVivo 2.0 and ATLAS.ti 5.0: a comparative review of two popular Qualitative DataAnalysis Programs. Sage Journals, Field Methods, 16(4), 439-464.

McGuinness, K. M. (2014). Institutional decision making: Empowering of the health system and economic transformation. American Psychologist, 69(8), 817-827.

Messick, S. (1980). Test validity and the ethics of assessment, American Psychologist, 35(1), 1012- 1027.

Mukonga, L. M. \& Awolusi, O. D. (2019). Strategic Leadership in the Post-Conflict States: A Study of the Democratic Republic of Congo (DRC), Journal of Social and Development Sciences, 10(4), 36-51.

Mpofu, M. \& Hlatywayo, C. K. (2015). Training and development as a tool for improving basic service delivery; the case of a selected municipality. Journal of Economics Finance and Administrative Science, 20(39), 133-136.

Ojasalo, J. \& Tähtinen, L. (2016). Integrating open innovation platforms in Public Sector Decision Making: Empirical Results from Smart City Research. Technology Innovation Management Review, 6(12), 38-48.

Peek, M. E., Lopez, F. Y., Williams, H. S., Xu, L. J., McNulty, M. C., Acree, M. E. \& Schneider, J. A. (2016). Development of a conceptual framework for understanding shared decision making among AfricanAmerican LGBT patients and their clinicians. Journal of General Internal Medicine, 31(6), 677-687.

Phillips, B. K., Prybutok, V. \& Peak, D. (2014). Determinants of task performance in a visual decision-making process. Journal of Decision Systems, 27(2), 175-182.

Posner, B. Z., Schmidt, H. W. (1994). An Updated Look at the Values and Expectations of Federal Government Executives. Public Administration Review, 54, 20-24.

Pugh, D., L. (1991). The Origins of Ethical Frameworks in Public Administration. In James S. Bowman, ed. Ethical Frontiers in Public Administration. San Francisco: Jossey-Bass.

Raziq, A. \& Maulabakhsh, R. (2015). Impact of Working Environment on Job Satisfaction. Procedia Economics and Finance, 23(4), 717-725.

Rohr, J. A. (1989). Ethics for Bureaucrats: An Essay on Law and Values, $2^{\text {nd }}$ ed. New York Marcel Dekker.

Senn, L. E. \& Childress, J. R. (2000). The Secret of a Winning Culture. New Delhi, India: Prentice - Hall of India.

TeleCongo. (2018). Summary of the session of the cabinet held on 27th December 2018. Available at: www.telecongo.cg (Accessed: 07/01/2019).

The World Bank Group. (2018). Understanding poverty. Available at: https://www.worldbank.org/en/topic/poverty (Accessed: 04/11/18).

Trip, G., Thijssen, J. G., Renkema, J. A. \& Huirne, R. B. M. (2002). Measuring managerial efficiency: the case of commercial greenhouse growers. Agricultural Economics, 27(2), 175-182.

University of Roehampton Online. (2015d). Centre for Student Success: Maths and Statistics for Research. Available at: http://success.roehamptononline.com/MathsAndStatisticsForResearch (Accessed: 26/12/17).

University of Roehampton/Laureate Online Education. (2016). Ethical Guidelines for Data Collection.

University of Roehampton Online. (2017b). UoRL Online Ethics Process. Available at: http://success.roehampton-online.com/ld.php?content_id=31454696 (Accessed: 7/12/17).

UNHCR. (2019). The Competency Framework. Available at: https://intranet.unhcr.org/en/hr/performance/policies-and-forms.html. (Accessed: 29/04/2019)

Van, W. M. (1996). The Sources of Ethical Decision Making for Individuals in the Public Sector. Public Administration Review, 56(6), 525-533.

Villasís-Keever, A. M., Márquez-González, H., Zurita-Cruz. N. J., Miranda-Novales, G. M., \& Escamilla-Núñez, A. (2018). Research protocol VII. Validity and reliability of the measurements. Revista Alergia México, 65(4), 414-421.

Vox, T. V. (2017). Over 66.000 practitioners are employed by the public service, 56-35

Yemane, T. (1967). Elementary Sampling Theory, Printice-Hall Inc. Englewood Cliffs: New Jersey, USA, 785790. 